\title{
From Photo to 3D to Mixed Reality: A Complete Workflow for Cultural Heritage Visualisation and Experience
}

\author{
Hafizur Rahaman $^{1 *}$, Erik Champion ${ }^{2}$, Mafkereseb Bekele ${ }^{3}$ \\ 1. Research Fellow, Faculty of Humanities, Curtin University, Australia. Email:
}

hafizur.rahaman@curtin.edu.au.Phone:+61-892663339,ORCID:0000-0003-08583821 .

2. UNESCO Professorial Chair in Cultural Heritage \& Visualisation, CIC and AAPI, Faculty of Humanities, Curtin University, Australia. Email:

erik.champion@curtin.edu.au,Phone: +61-892662614,ORCID:0000-0002-53626176.

3. Mafkereseb Kassahun Bekele, PhD Student, Curtin University. Email: mafkereseb.bekele@postgrad.curtin.edu.au.

\section{Acknowledgements}

This study was supported by a 2018 MCCA Small Grant, granted by the by School of Media, Culture and Creative Arts (MCCA), Curtin University, Perth, Australia, and as part in-kind support from the UNESCO Chair in Cultural Heritage and Visualisation. 


\title{
From Photo to 3D to Mixed Reality: A Complete Workflow for Cultural Heritage Visualisation and Experience
}

\begin{abstract}
:
The domain of cultural heritage is on the verge of adopting immersive technologies; not only to enhance user experience and interpretation but also to satisfy the more enthusiastic and tech-savvy visitors and audiences. However, contemporary academic discourse seldom provides any clearly defined and versatile workflows for digitising 3D assets from photographs and deploying them to a scalable 3D mixed reality $(\mathrm{MxR})$ environment; especially considering non-experts with limited budgets. In this paper, a collection of open access and proprietary software and services are identified and combined via a practical workflow which can be used for 3D reconstruction to MxR visualisation of cultural heritage assets. Practical implementations of the methodology has been substantiated through workshops and participants' feedback. This paper aims to be helpful to non-expert but enthusiastic users (and the GLAM sector) to produce image-based 3D models, share them online, and allow audiences to experience 3D content in a MxR environment.
\end{abstract}

\section{Introduction}

Digital documentation and preservation of historical and cultural artefacts has increasingly become an international priority in recent years, because of concerns regards the destruction and damage inflicted on internationally recognised heritage assets located in Afghanistan, Syria, Iraq, and most recently, in Brazil. On the other hand, the emergence of cultural computing (CC) (Haydar et al., 2011; Wang, 2009) and advancement in computer technologies have helped to smoothen the procedure and production of 3D documentation, representation and dissemination of cultural heritage data (Barsanti et al., 2014; Portalés et al., 2009). In particular, the rise of affordable techniques (such as image-based photo modelling) and free and open source software (FOSS) is remarkable.

The domain of cultural heritage has also extended its application of immersive technologies; with augmented reality (AR), virtual reality (VR) and mixed reality (MxR) technologies supporting sensory experiences through a combination of real and digital content. As a reflection of the present trends in the digitisation of 3D heritage assets, we can quickly find studies and research on 3D modelling and their application in AR/VR (Bruno et al., 2010; Rua and Alvito, 2011). Ample studies have been published on image-based modelling software analysing their performance (Durand et al., 2011; Grussenmeyer and Al Khalil, 2008; Wang, 2011), accuracy in 3D production (Bolognesi et al., 2014; Deseilligny et al., 2011; Oniga et al., 2017), algorithms (Knapitsch et al., 2017), and scalability (Knapitsch et al., 2017; Nguyen et al., 2012; Santagati et al., 2013). Additionally, we can also find several studies on approaches in application and use of VR/AR in museums and exhibitions; applied from various perspectives such as learning in the classroom (Wu et al., 2013), group use of AR in a public space (Barry et al., 2012), developing virtual exhibitions (Anderson et al., 2010), supporting interactive experiences through 3D reconstructions (Gkion et al., 2011), and providing low-cost solutions for 3D interactive museum exhibitions (Monaghan et al., 2011) etc.

However, it is rare to find a complete production pipeline, or guide for non-experts who are interested in digitising, sharing, and viewing 3D content in a mixed reality $(\mathrm{MxR})$ environment; despite having a restricted budget. To address the above issues, we present a methodology on 3D digitisation to MxR visualisation of cultural heritage assets; based on proprietary and open access software and service. We present two cases to explain the workflow. Photographs are taken from both mobile phone and digital camera. Image-based modelling technique has been used for point cloud generation (with Regard 3D). 3D mesh has been generated and optimised from the obtained point cloud (with Mesh Lab) and later uploaded online for public sharing and visualizing in AR/VR (with Sketchfab). Finally, development of interactive visualisation in a MxR environment (Microsoft HoloLens) has been achieved with a game engine (Unity 3D and MS Visual Studio). The aim of this paper is to help non-expert users to understand the methodology and follow the workflow to produce image-based 3D models, share them online, and experience the digital assets in VR/AR and even in MxR environment such as HoloLens. 


\section{Proposed methodology and detail workflow}

The reality-virtuality continuum presented by Milgram and Kishino (1994) provided a conceptual spectrum of visualisation technologies spanning the real world and virtual world (figure 1), and introduced the core concept of Virtual Reality (VR), Augmented Reality (AR), Augmented Virtuality (AV) and Mixed Reality (MxR). AR enhances users' perception and understanding of the real world by superimposing virtual information and object on top of the view of the real world. VR on the other hand, completely detach the viewer from the real world with a computer-generated environment and offers artificial presence to that virtual world (Carigniani 2011). Milgram and Kishino (1994) defined MxR as a subclass of VR that merges the real and the virtual worlds. However, there are instances where the terms AR and MxR are used interchangeably (Papagiannakis 2018, Raptis 2018).

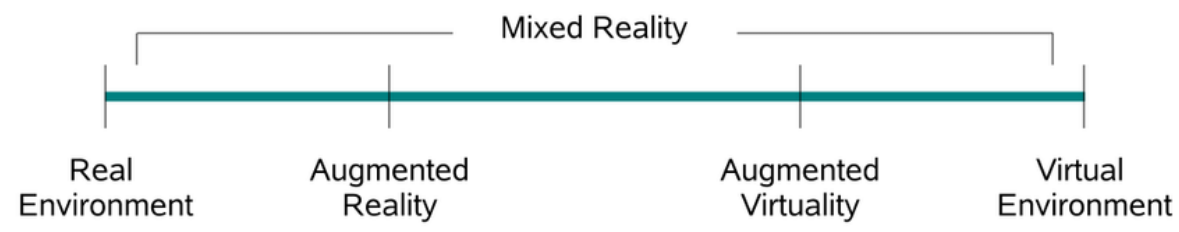

Figure 1. The reality-virtuality continuum presented by Milgram and Kishino (1994).

In this paper, we present a methodology of producing 3D digital assets from photographs and later deploy it in a MxR environment with interactivity in supporting cultural heritage visualisation and learning. The 3D models are obtained by using image-based photo modelling techniques (photogrammetry), and the MxR environment is developed in HoloLens. We demonstrate a detailed workflow (figure 2) starting from photo acquisition to all the way to $3 \mathrm{D}$ reconstruction and $\mathrm{AR} / \mathrm{VR} / \mathrm{MxR}$ visualisation. Additionally, we point out best practice and explain how to avoid some common pitfalls.

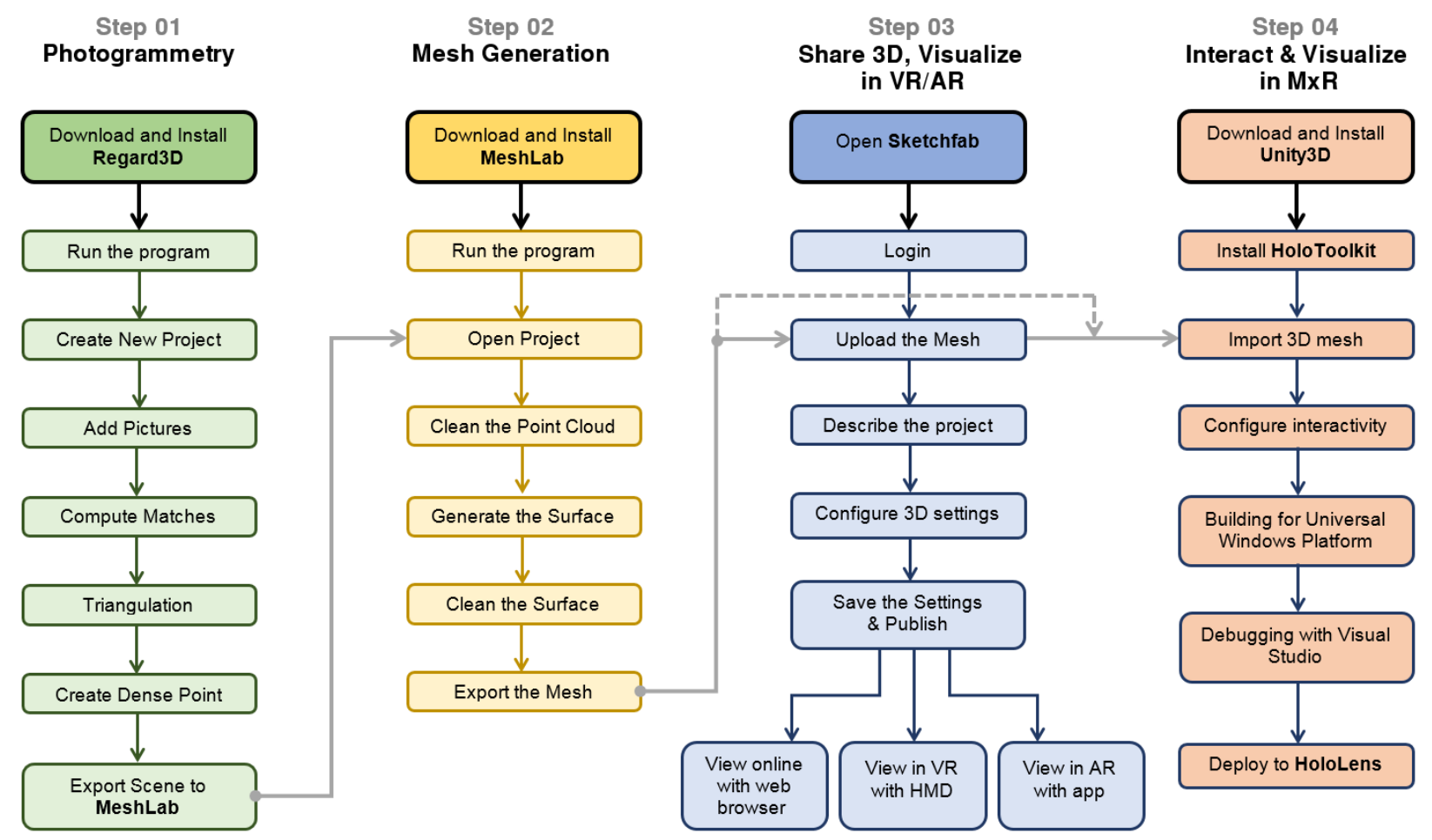

Figure 2. The overall workflow of 3D modelling to mixed reality visualisation.

\section{Photogrammetry/Image based 3D modelling}

Based on the software/service, image based 3D modelling can be done with the support of remote/cloud computing or in local machine. Software or services such as ARC3D and Autodesk Remake use the 
power of cloud computing to carry out the data processing. In contrast, Regard3D, PhotoScan, Aspect3D, 3DF Zephyr, 3D SOM Pro etc. process the data on local client machines. Scope of this paper doesn't cover the cloud processing method; the workflow will focus only on those software/applications that run on a local PC workstation. Generally these software packages follow six steps to produce 3D reconstructions/3D models, which includes - (1) Image acquisition (or adding photos), (2) Feature detection, matching, triangulation (or align photos), (3) Sparse reconstruction, bundle adjustment (or point cloud generation), (4) Dense correspondence matching (or dense cloud generation), (5) Mesh/surface generation, and (6) Texture generation. A few software packages also offer cloud/mesh editing within a single package.

\subsection{Image Acquisition:}

Image-based 3D reconstruction software creates 3D point cloud with camera poses from uncalibrated photographs. The software determines the geometric properties of objects from photographic images. This process, therefore, requires comparing and reference points or matching pixels across a series of photographs. Quality and certain number of photographs are consequently needed to allow the surface to process, match and triangulates visual features and further generating $3 \mathrm{D}$ point-cloud. A mobile phone camera (iPhone 6,8 megapixels) has been used for photo shooting and twenty-two photos are taken for case-1. Alternatively, fifty photographs for case-2 have been captured with a Canon 600D camera. Photos are taken with the right amount of overlap while repositioning the camera for every photo (more information about image acquisition and associated setting can be found in a paper by Lab, 2018).

\subsection{Point Cloud Generation:}

\subsubsection{Selection of the software:}

Structure from Motion (SfM) is just one of many techniques for 3D reconstruction of objects and artefacts, and most often been recommended (Nikolov and Madsen, 2016). A wide variety of 3D modelling programs are available based on SfM; ranging from simple home-brew systems to high-end professional packages.

Table 1: Benchmarking of FOSS with PhotoScan (adopted from Rahaman and Champion, 2019).

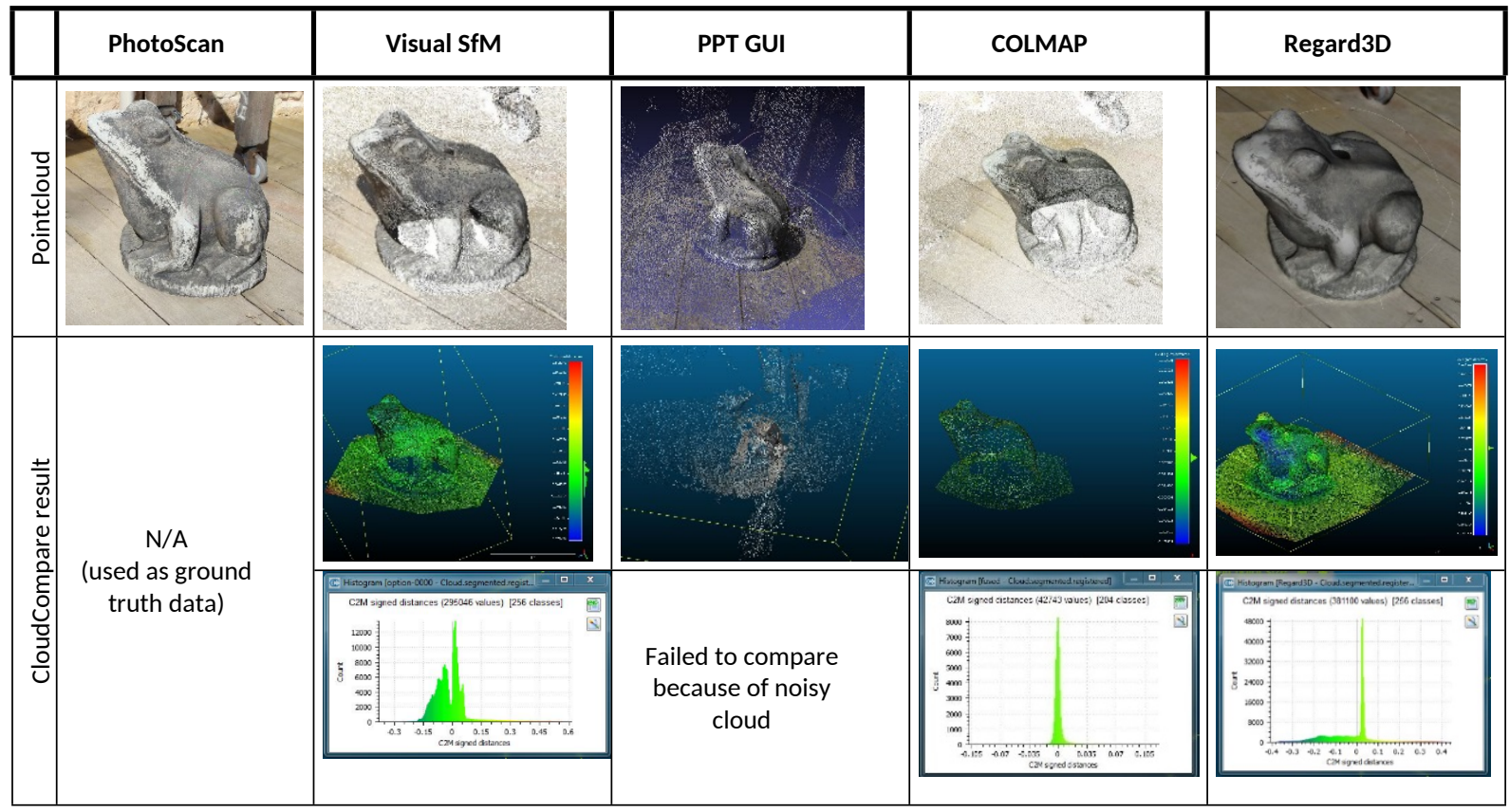

A study from Rahaman and Champion (2019) attempted to measure the quality and accuracy of produced point-clouds by four Free and Open Source (FOSS) software with a popular commercial one. This study shows that FOSS can create a significant good result/point cloud compared to a commercial product (figure 3), and it recommends Regard3D. As visualisation of cultural heritage is the primary 
objective of this study, acquisition of a visually appealing 3D model generated from a low-cost solution, therefore, has been given priority. Herein Regard3D has been used for creating a 3D point-cloud from the datasets (i.e. a set of photographs).

\subsubsection{Point cloud generation}

Regard3D is a free and open source structure-from-motion program that supports multiple platforms (Windows, OS X, and Linux). A simple and straightforward graphic user interface (GUI) presents the details of whatever results it produced highlighted in the left tree view. Experimenting with settings is thereby much easier since the user only has to click on a result to see a list of the arguments used to generate it, as well as the running time of that selected step. Similar to other software, the user needs to set a project path first and input a name to start a project (figure 3).

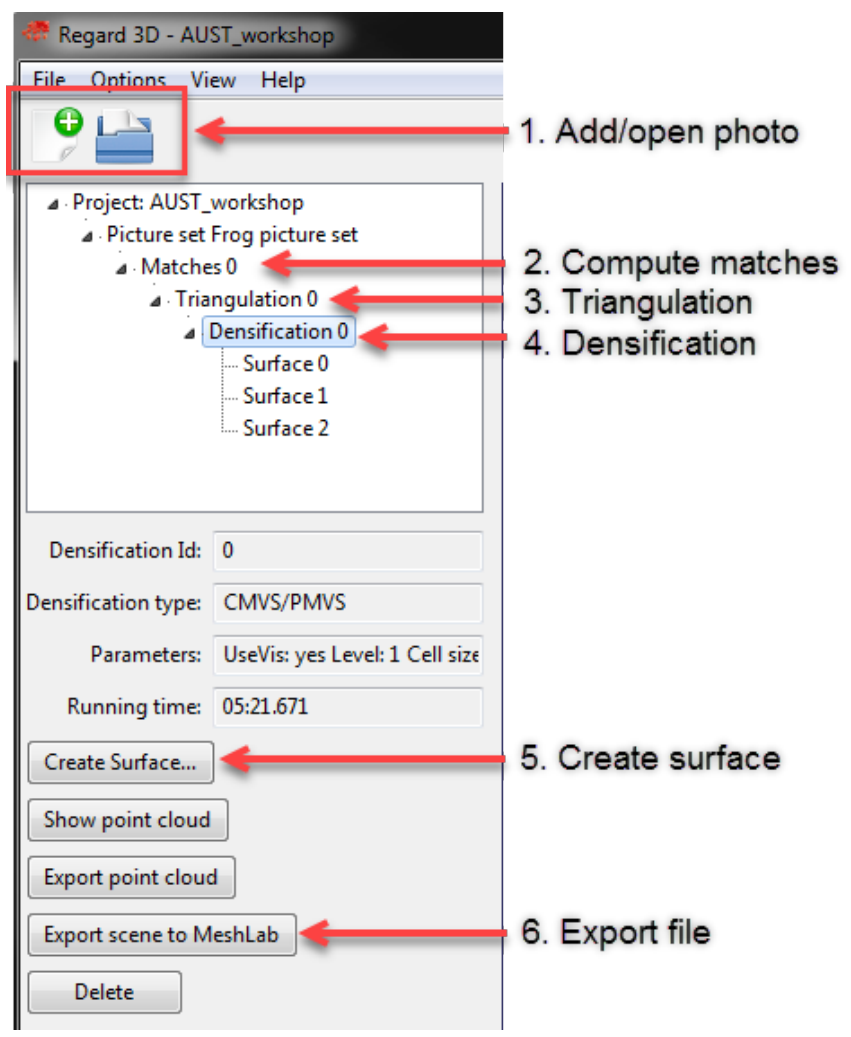

Figure 3. Workflow offered by Regard3D GUI.

Photographs are required to be set (step 1) and matches computed (Step 2). Next up is camera registration. In other words the process of determining each camera's position and orientation in the scene (Step 3), can be achieved by selecting the match results and click Triangulation. Based on this simple sparse point cloud, users can "densify" the triangulation result (Step 4). From the tree view, it is possible to highlight the result of the last step and choose 'Create dense point cloud'. The dense could (*.ply, *.pcd) can be exported at this stage. Users can also generate a mesh by clicking Create Surface (Step 5). If the user has used the CMVS/PMVS in the previous stage, then 'Poisson reconstruction' becomes the only option to create the surface. Colourisation method can be selected either as coloured vertices or texture. At this stage, the user can export the generated surface as *.obj file or directly export to MeshLab as *.mtl file format (step 6). 


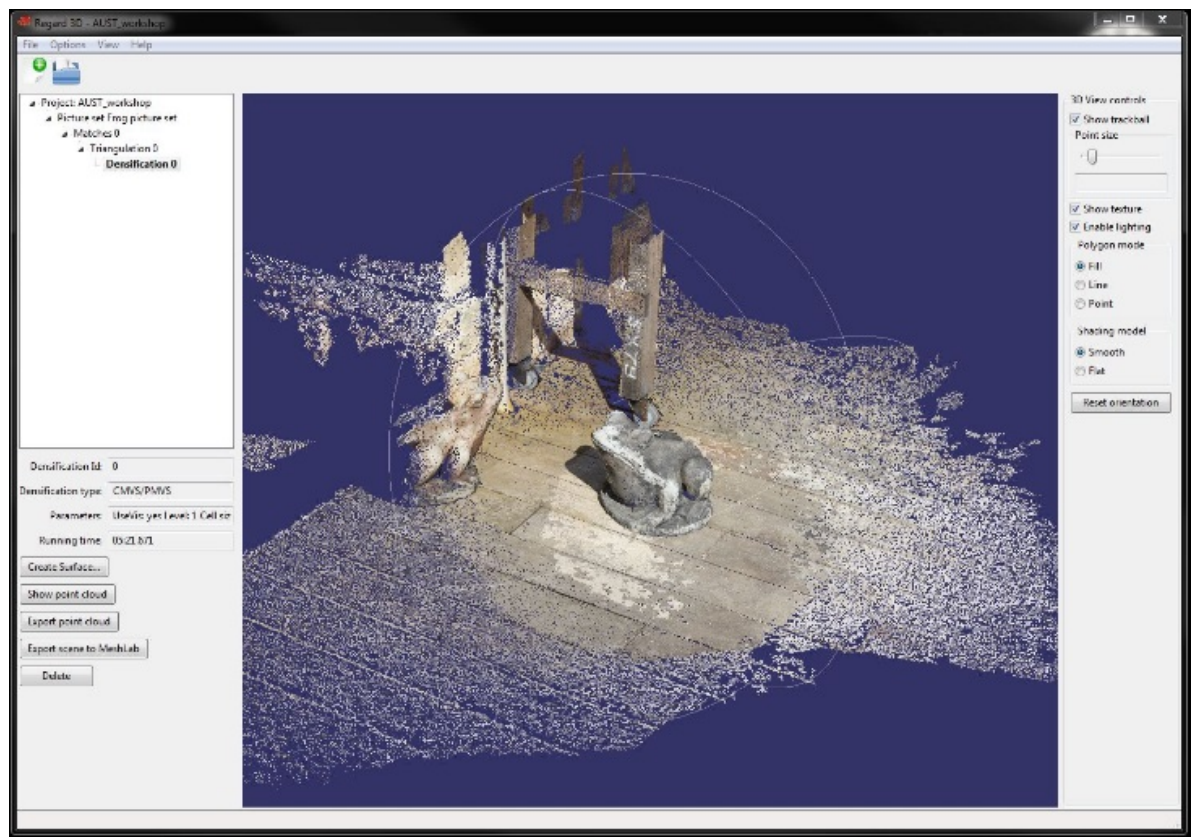

Figure 4. Dense point cloud created by Regard3D.

\subsubsection{Result/Outcome}

The computation details and output of the three cases are presented in table 2.

Table 2: Point cloud generation with Regard 3D

\begin{tabular}{|c|c|c|}
\hline Original object & Generated 3d/point-cloud & Process time \\
\hline \multicolumn{3}{|l|}{ Case Study 01} \\
\hline 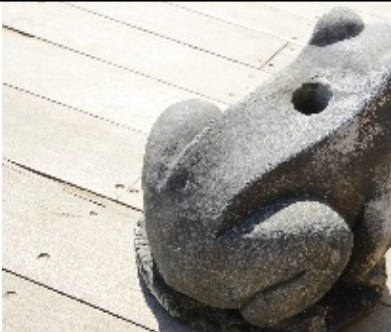 & & $\begin{array}{l}\text { Number of photos: } 22 \\
\text { Image matching: } \\
2 \mathrm{~m} 12.649 \mathrm{~s} \\
\text { Triangulation: } 34.892 \mathrm{~s} \\
\text { Densification: } \\
\text { CMVS/PMVS - } \\
4 \mathrm{~m} 27.982 \mathrm{~s} \\
\text { Surface generation: } 1 \mathrm{~m} \\
2.725 \mathrm{~s} \\
\text { Total time: } 8.5 \mathrm{~min}\end{array}$ \\
\hline \multicolumn{3}{|l|}{ Case Study 02} \\
\hline 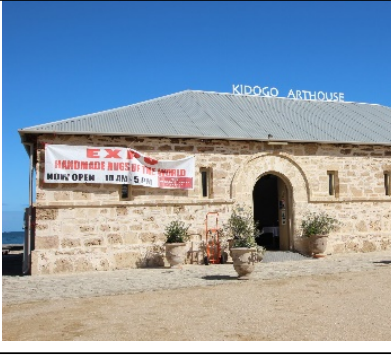 & (1) & $\begin{array}{l}\text { Number of photos: } 50 \\
\text { Image matching: } \\
27 \mathrm{~m} 41.151 \mathrm{~s} \\
\text { Triangulation: } 2 \mathrm{~m} \\
50.710 \mathrm{~s} \\
\text { Densification: } \\
\text { CMVS/PMVS - } \\
20 \mathrm{~m} 38.443 \mathrm{~s} \\
\text { Surface generation: } 1 \mathrm{~m} \\
4.381 \mathrm{~s} \\
\text { Total time: } 52 \mathrm{~m} 21 \mathrm{~s}\end{array}$ \\
\hline
\end{tabular}

Nearby vegetation, trees and other buildings/structures often obstruct views for taking photographs of a heritage building. Making a 3D model of a whole building/architecture based on image based photo modelling technique therefore is often challenging. Only isolated buildings and structures are suitable for the application of this image-based 3D modelling technique. Additionally, a larger file takes more time in computation, we avoided larger file sizes in this study. The 3D model of the 'Frog' sculpture was smaller and easier for testing the workability of the methodology and for conducting the workshop. 


\section{Mesh Generation and Editing}

A mesh is a discrete representation of a geometric model in terms of its geometry, typology and associated attributes (Comes et al., 2014). We used MeshLab (http://meshlab.net), a free and open source software to develop mesh by the generated point-cloud from Regard3D. After importing the point-cloud in the workspace, it requires cleaning (noise, outliers and irrelevant points). MeshLab provides various tools for selection and removal of points/vertexes.

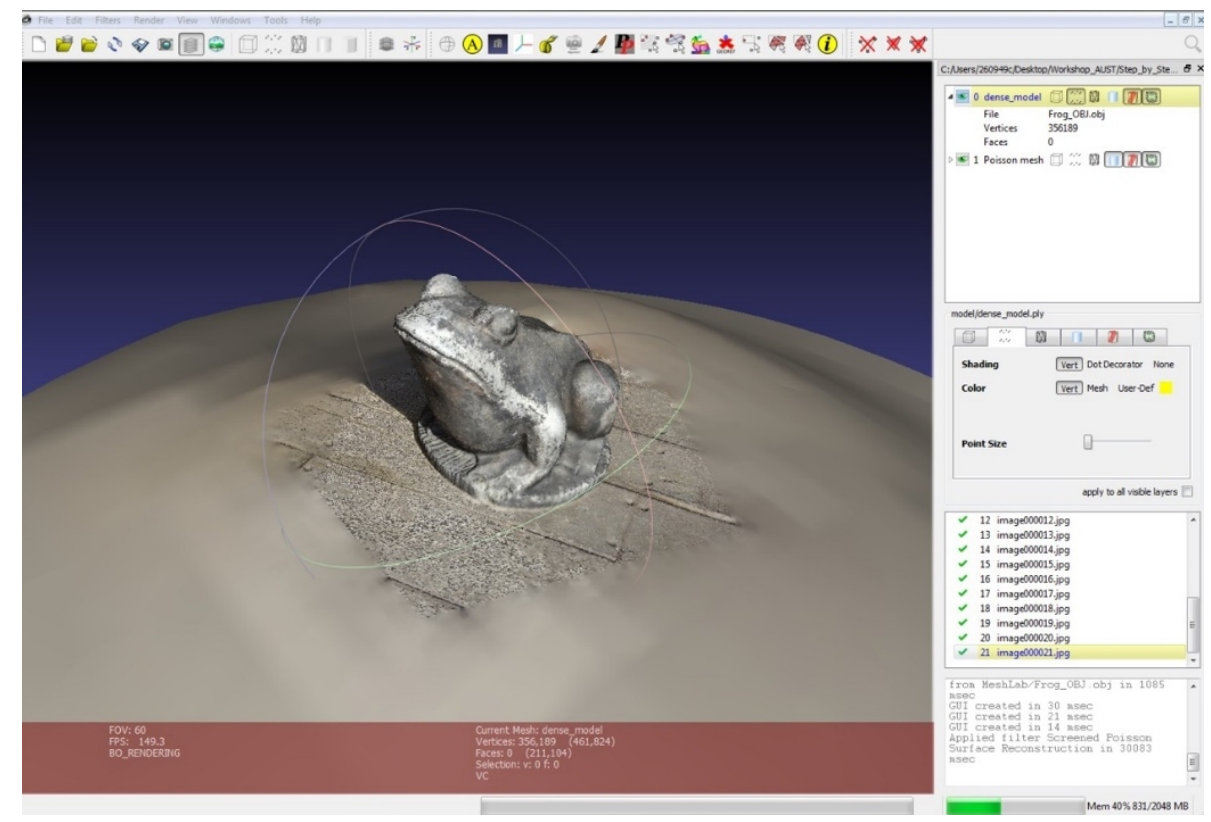

Figure 5. New surface (Poisson mesh) applied to the point cloud.

MeshLab also offers various tools for developing surface reconstruction (or mesh generation) such as Ball Pivoting (Bernardini et al., 1999), VCG (Curless and Levoy, 1996) (ISTI Visual computer Lab), and Screened Poisson Surface Reconstruction (Kazhdan and Hoppe, 2013). We used the Poisson algorithm to generate the mesh (figure 4). Additional clearing of the surface may be required at this stage if the process creates unintended surfaces. The acquired mesh can be exported or 'mesh simplification' and 'cap hole' steps can be applied to enhance the 3D model. Mesh simplification reduces the number of polygons while keeping the shape as close as the original. As the number of polygons is reduced, the processing time decrees accordingly. 'Cap holes' on the other hand is selfexplanatory; it closes the holes where the previous mesh generation fails to provide/create any surface/polygon.

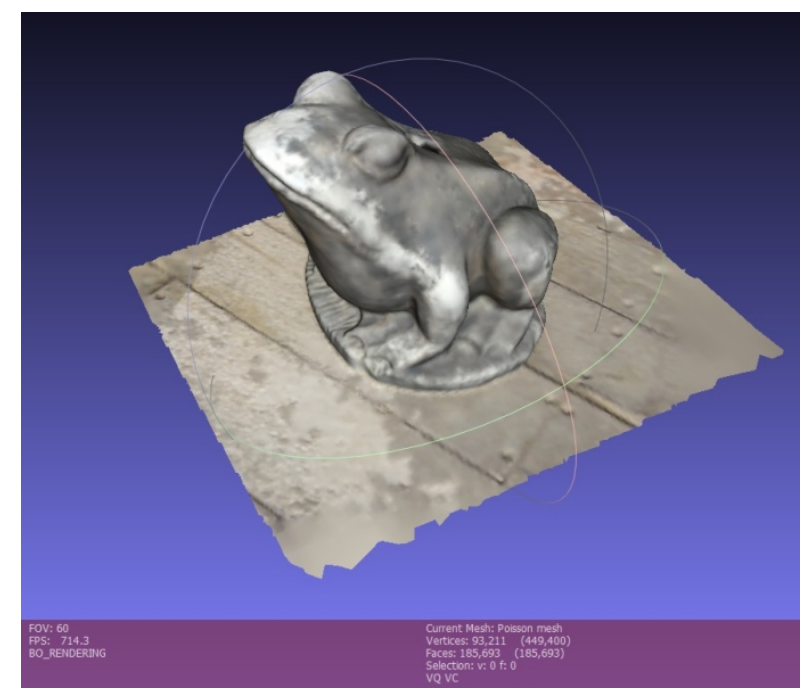

Figure 6. 3D model after manual cleaning. 
Texturing is the operation that offers visual skin/membrane coverage of the $3 \mathrm{D}$ models, so that the virtual objects resemble the original. MeshLab can export a wide range of file formats, which supports textures (e.g. *.x3d, *.obj) and vertex/points colour (*.ply). Although most commonly .obj, .vrml, $.3 \mathrm{dxml}$ and .dae are used for AR applications (Comes et al., 2014), we have exported the mesh as 'Stanford Polygon File Format (*.ply)' for further use.

\section{Sharing and visualizing the 3D models in AR/VR}

\subsection{Storing the 3D model}

At the time of writing this article, we could not find a clear and foolproof way to preserve/store 3D assets. There are remarkable commercial, public, and hobbyist 3D repositories, ranging from local institutions to international ones; such as CARARE, Europeana, Smithsonian, TurboSquid, Sketchfab etc. It is also clear that despite recent EU and North American moves to create archives and digital heritage infrastructure; 3D models are still not fully accessible to general public (Champion, 2018). Most of the institutional repositories only allow downloading contents with restricted file format. In some cases, only *.pdf files with embedded 3D (such as in CARARE) are allowed. Additionally, it is often difficult to find models from specialised cultural heritage institutional repositories, as they are typically not connected with external sites or portals. On the other hand, commercial repositories often lack data provenance and metadata. However, commercial repositories can provide consistent formats and protocols, and 3D models are relatively easier to find and access. But most of these portals (both commercial and non-commercial) rarely provide other related information and resource links for further study or use.

Table 3: Selected 3D repositories with common features

\begin{tabular}{|c|c|c|c|c|c|}
\hline Name & $\begin{array}{l}\text { Supported file } \\
\text { format }\end{array}$ & Fees & Accessibility & Data size & $\begin{array}{l}\text { 3D model } \\
\text { display }\end{array}$ \\
\hline \multicolumn{6}{|c|}{ Public/institutional repositories } \\
\hline $\begin{array}{l}\text { Smithsonian } \\
\text { (http://3d.si.edu) }\end{array}$ & $\begin{array}{l}\text { STL, OBJ, Single } \\
\text { ASCII point cloud }\end{array}$ & Free & $\begin{array}{l}\text { With few exceptions, } \\
\text { SIx3D offers access to } \\
\text { the data sets }\end{array}$ & $\begin{array}{l}\text { Download limit } \\
\text { is not known }\end{array}$ & $3 \mathrm{D}$ \\
\hline $\begin{array}{l}\text { Three D Scans } \\
\text { (http://threedscans.co } \\
\text { m/info) }\end{array}$ & OBJ, STL & Free & $\begin{array}{l}\text { No copyright } \\
\text { restrictions }\end{array}$ & Unlimited & $\begin{array}{l}\text { 2D, 3D, } \\
\text { animated gif }\end{array}$ \\
\hline $\begin{array}{l}\text { CyArk } \\
\text { (http://www.cyark.org }\end{array}$ & $\begin{array}{l}\text { LiDAR, point cloud, } \\
\text { photogrammetric } \\
\text { imagery }\end{array}$ & $\begin{array}{l}\text { Free, require } \\
\text { online } \\
\text { application }\end{array}$ & $\begin{array}{l}\text { Licensed under a } \\
\text { Creative Commons } \\
\text { Attribution-Non- } \\
\text { commercial } 4.0 \\
\text { International License }\end{array}$ & $\begin{array}{l}\text { Varies, prior } \\
\text { permission } \\
\text { required }\end{array}$ & $2 \mathrm{D}, 3 \mathrm{D}$ \\
\hline $\begin{array}{l}\text { Europeana } \\
\text { http://www.europeana } \\
\text { eu/portal/en }\end{array}$ & $\begin{array}{l}\text { Jpeg, GIF, PNG, } \\
\text { PDF, Plain ASCII, } \\
\text { MP3, MPEG, AVI, } \\
\text { FBX, mtl, OBJ }\end{array}$ & Free & $\begin{array}{l}\text { Most databases are not } \\
\text { accessible anymore }\end{array}$ & Not known & $2 \mathrm{D}, 3 \mathrm{D}$ \\
\hline \begin{tabular}{|l|} 
EPOCH \\
(http://epoch- \\
net.org/site) \\
\end{tabular} & Pdf & Free & Not known & Unlimited & $2 \mathrm{D}$ \\
\hline $\begin{array}{l}\text { CARARE } \\
\text { (http://pro.carare.eu) }\end{array}$ & PDF, 3D PDF & Free & Not known & Unlimited & $\begin{array}{l}\text { 3D inside } \\
\text { PDF }\end{array}$ \\
\hline $\begin{array}{l}\text { NASA 3D } \\
\text { Resources } \\
\text { (https://nasa3d.arc.nas } \\
\text { a.gov/) }\end{array}$ &. stl, .3ds & Free & $\begin{array}{l}\text { Non-Commercial Use } \\
\text { only }\end{array}$ & Unlimited & $2 \mathrm{D}$ \\
\hline \multicolumn{6}{|c|}{ Commercial repositories } \\
\hline $\begin{array}{l}\text { Sketchfab } \\
\text { (https://sketchfab.com }\end{array}$ & $\begin{array}{l}50 \text { popular file } \\
\text { formats }\end{array}$ & $\begin{array}{l}\text { Basic \& } \\
\text { Education } \\
\text { access are } \\
\text { Free }\end{array}$ & $\begin{array}{l}\text { Varies between paid } \\
\text { and free model }\end{array}$ & $\begin{array}{l}\text { Limit based on } \\
\text { membership, } \\
\text { Unlimited } \\
\text { download }\end{array}$ & $\begin{array}{l}2 \mathrm{D}, 3 \mathrm{D}, \mathrm{AR}, \\
\mathrm{VR}\end{array}$ \\
\hline
\end{tabular}




\begin{tabular}{|c|c|c|c|c|c|}
\hline $\begin{array}{l}\text { MyMiniFactory } \\
\text { (https://www.myminif } \\
\text { actory.com) }\end{array}$ & $\begin{array}{l}54 \text { popular file } \\
\text { formats }\end{array}$ & $\begin{array}{l}\text { Free/paid } \\
\text { option to } \\
\text { download } \\
\text { and print }\end{array}$ & & $\begin{array}{l}\text { Unlimited } \\
\text { uploads }\end{array}$ & $2 \mathrm{D}$ \\
\hline $\begin{array}{l}\text { Blendswap } \\
\text { (https://www.blendsw } \\
\text { ap.com) }\end{array}$ & $\begin{array}{l}37 \text { popular file } \\
\text { formats }\end{array}$ & Free & $\begin{array}{l}\text { Varying Creative } \\
\text { Commons }\end{array}$ & $\begin{array}{l}\text { Free } 200 \mathrm{MB} \\
\text { download/m, } \\
\text { Upload limit } 90 \\
\text { MB }\end{array}$ & $2 \mathrm{D}$ \\
\hline $\begin{array}{l}\text { 3D Warehouse } \\
\text { (https://3dwarehouse.s } \\
\text { ketchup.com) }\end{array}$ & skp & Free & $\begin{array}{l}\text { General Model License } \\
\text { Agreement }\end{array}$ & $\begin{array}{l}\text { 50MB (max) } \\
\text { upload }\end{array}$ & $2 \mathrm{D}, 3 \mathrm{D}$ \\
\hline $\begin{array}{l}\text { TurboSquid } \\
\text { (https://www.turbosqu } \\
\text { id.com) }\end{array}$ & $\begin{array}{l}16 \text { popular file } \\
\text { formats }\end{array}$ & $\begin{array}{l}\text { Free and } \\
\text { paid }\end{array}$ & $\begin{array}{l}\text { Model Licenses: } \\
\text { Various }\end{array}$ & No restriction & $2 \mathrm{D}, 3 \mathrm{D}$ \\
\hline
\end{tabular}

It is relatively apparent that (at the time of writing this paper), Sketchfab is a commercial platform with flexible and versatile hosting that can support the general public, small institutes and non-profit organisations to host, minor edit, share, trade and showcase their 3D models. These models can later be shared online and viewed in AR/VR with the supplied application. The other commercial repositories such as Turbo Squid, ShareCG, MyMiniFactory and Blendswap are mostly for the trading of 3D models and are not intended for preservation. Additionally, they charge fees on trading and may not interested in archiving (as their archiving policy is not clear).

\subsection{Selection of the visualisation (AR/VR) platform}

There are number of software frameworks at present to support AR/VR especially suited for cultural heritage. The first criterion is the choice of a single package or solution that supports non-expert users with a limited or restricted budget. Additionally, it is difficult to find a compelling platform or tools that accept a wide variety of file formats, supports cross-platform deployment and visualisation.

There are certain points of overlap between AR and VR since some existing development platforms are suitable for both experiences. A study from Mafkereseb (2018) on most commonly used current AR/VR frameworks has featured their strengths and weaknesses in various settings. However, this study is limited to exploring the tools and not the whole pipeline. Comes et al. (2014) studied 3D AR, AndAR and $\mathrm{VaD} \mathrm{AR}$, however, this study focused on simplification of the 3D models rather than evaluating any AR/VR platform. The study from Krevelen et al. (2010) presents the technicalities, development history and characteristics of a wide range or AR technologies.

Portales et al. (2009) have explored various AR platforms and later adopted BazAR (a vision based open source library) to deploy their 3D content. However, to use BazAR user needs to have vision based relative technical knowledge of programming. The workflow adopted by Taboada (2011) for visualising 3D point cloud data in VR only, used OGRE 3D engine (game engine). Studies from Amin et al. (2015) and Guidazzoli et al. (2017) have showcased feature list comparison of various software development kit (SDK) for AR visualisation. Recently, AR toolkits based on visual-inertial odometry tracking have been gaining attention. In particular, the Google ARCore and Apple ARkit look promising. However, it is often difficult for a non-technical person to overcome the steep learning curve in order to use their offered SDKs.

Although X3D and three.js models can run without hindrance in HTML formatted web pages, the issue of choosing 3D file formats best suited for archiving or displaying is still a big challenge in the digital heritage domain. 3DHOP (Potenziani et al., 2015) and Sketchfab are prominent among the relatively few popular services that provide storing, viewing and exhibiting of 3D models online. The open source and free 3DHOP is, however, restricted to *.NXS and *.PLY file format only. Sketchfab, on the other hand, supports more than 50 formats and the free 'basic access' also allows 3D models with a maximum of 50MB for uploading files (at the time of writing this paper). A comprehensive study on 3D web applications by Guidazzoli et al. (2017) also reveals that Sketchfab competes very well against others for its documentation, ease of learning, GUI, reliability and overall graphics quality. We have adopted Sketchfab in the workflow for online sharing and visualisation of the above mentioned 3D models. 


\subsection{AR/VR visualisation with Sketchfab}

Sketchfab supports 50 extensions (as od 30 October, 2017), including compressed archives such as ZIP, RAR and 7z. The GUI offered by Sketchfab for the user dashboard is simple and easy to use. First, the user is required to create a user account in order to upload the 3D content. Generating an account is also possible by signing up with Facebook, Google and Twitter while bypassing the default online form. Sketchfab generally compresses the file first and then starts uploading to the server. We have used the *.ply file saved previously from MeshLab.

The system asks for user input/information regarding the model name, description, categories and keywords as metadata. Next, it starts regenerating and take the user to the '3D Setting' mode. Sketchfab's GUI for 3D Settings offers various settings to adjust/control the model (figure 7). After getting the desired output the user can press the 'Save Settings' and 'Publish' button to finalise the process.

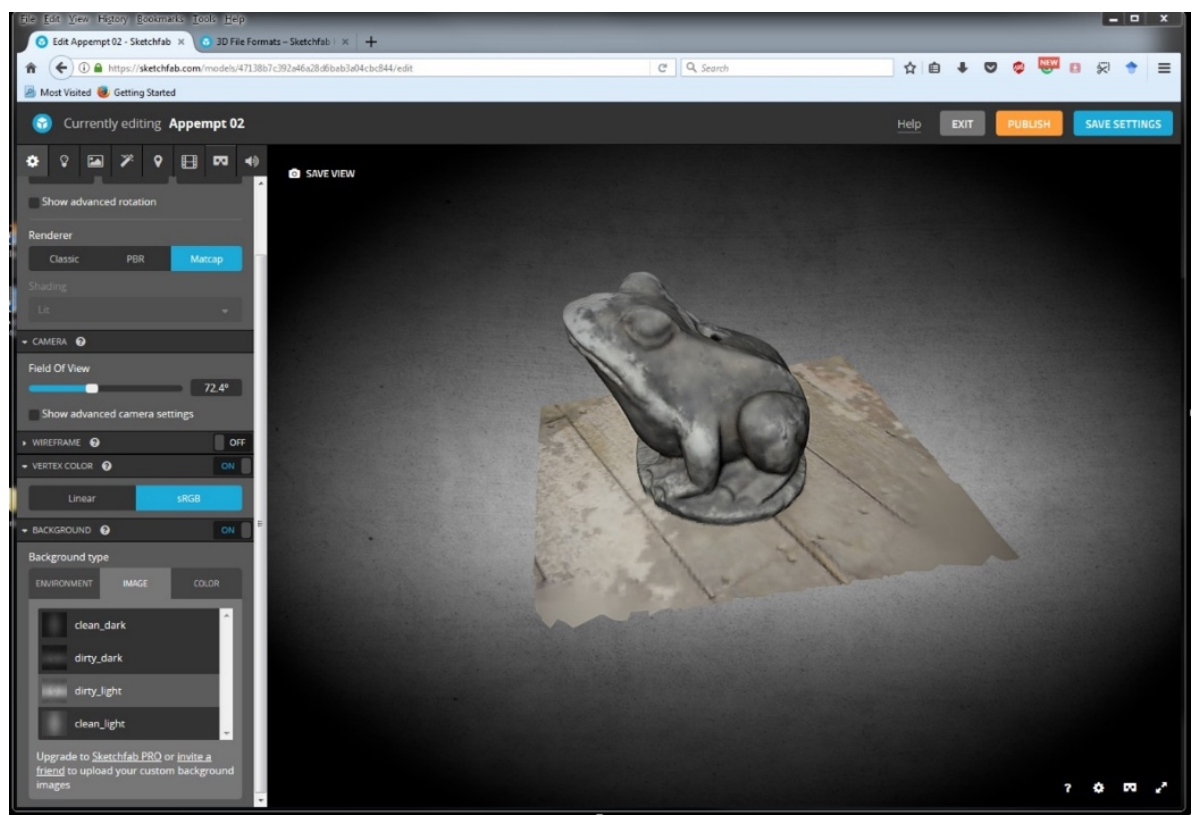

Figure 7. GUI for 3D settings offered by Sketchfab.

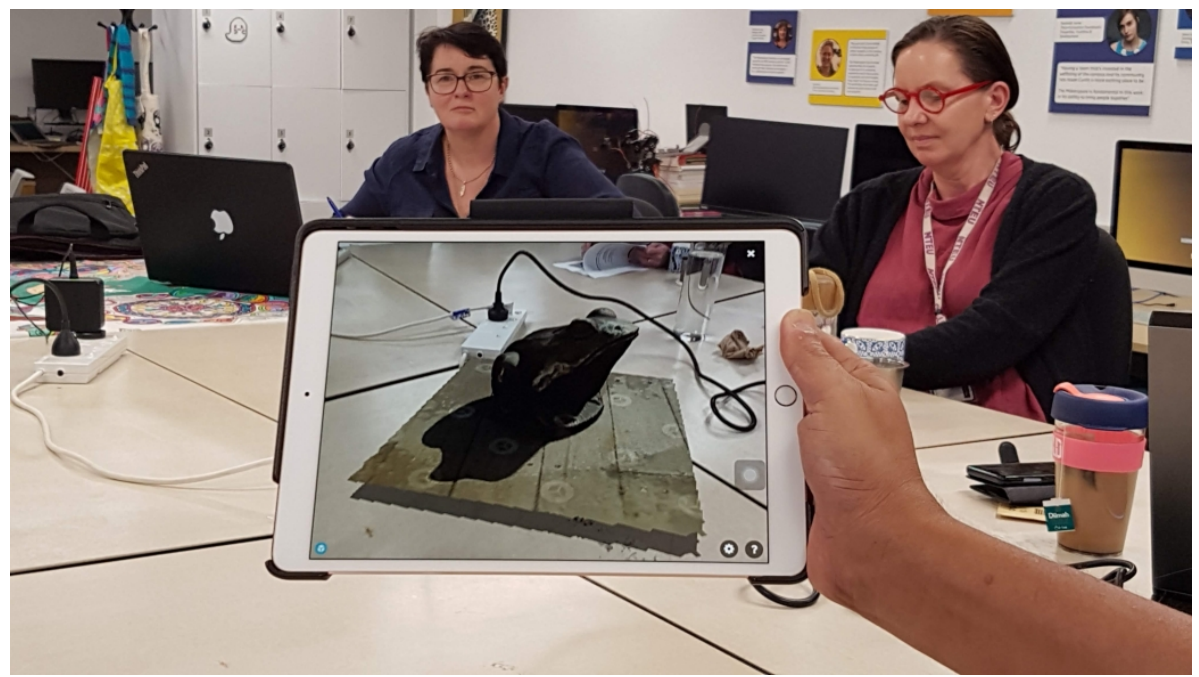

Figure 8. View the 3D in AR with Sketchfab app.

The universal 3D VR viewer supported by Sketchfab works on most operating systems (Windows, Mac, Linux, iOS and Android) without any required plugin. A user can embed 3D or VR models on any website, forum, or even in Facebook to share their content online. Peers can browse in 3D or VR without leaving the user's own website. The 3D models can also be viewed in VR using various HMD such as 
Vive, Rift, Gear VR, or Cardboard navigation modes. Most interestingly, via the Sketchfab app installed in a compatible mobile device, one can also view the $3 \mathrm{D}$ in $\mathrm{AR}$ (figure 8).

\section{Developing interactivity and visualize in a MxR environment}

Mixed Reality (MxR) blends the real-world with the virtual world. It combines interactivity and immersion and offers immersive-interactive experience to view the real-virtual world (Papaginnakis 2018). MxR, therefore, aims to unite different properties of the Milgram and Kishino's (1994) continuum into a single immersive reality experience. Magic Leap, Meta 2, HoloLens are but a few of the many current popular standalone head mounted displays (HMD) that offer a MxR experience. There are some other alternatives (cheaper solutions) in the market such as Holoboard and Mira, which use a smartphone for processing the data and visualisation. However, they are still in their development stage and comparison with the more established group is out of the scope of this present study.

Microsoft HoloLens is an optical see-through Head-Mounted- Display (HMD) developed mainly for $\mathrm{AR} / \mathrm{MxR}$ experiences. The device can use sensual, and natural interface commands through gaze, gesture, and voice. Gaze commands, such as head-tracking, allows the user to bring application focus to whatever the user is perceiving. Various gestures such as bloom, air tap and pinch are supported for multiple interactions with the virtual object or interface. Any virtual object or button can be selected using an air tap method, similar to clicking an imaginary computer mouse. The tap and pinch can also be used for a drag simulation to move a virtual object. Users can access the shell/interface through a "bloom" gesture. Similar to pressing a Windows key on a Windows keyboard or tablet. Voice commands can also be used to activate actions (source: https://www.microsoft.com/en-us/hololens/hardware, access date 04 April 2019).

A large number of domains are utilising HoloLens for diverse application areas. Even if the utilisation of HoloLens isn't markedly observed in the Cultural Heritage $(\mathrm{CH})$ domain, the last two years have witnessed few Virtual Heritage (VH) applications that were developed using HoloLens. These exemplary HoloLens based applications include Baskaran (2018), Bottino et al., (2017), Pollalis et al., (2017), Pollalis, Gilvin, et al. (2018), Pollalis, Minor, et al. (2018), Scott et al. (2018). However, these articles focus on the experiential aspect of MxR in VH rather than the technical and procedural details that could be of a huge benefit to domain's professionals in terms of developing similar experiences as presented in the articles. In this regard, our paper discusses the major steps required to deploy 3D models into HoloLens for a mixed reality experience. The discussion below has been organised for non-expert users of the technology.

\subsection{Setting the environment with Unity 3D and importing 3D model}

As briefly discussed at the introductory section, 'Unity 3D' (or Unity) is a popular cross-platform game engine widely used to develop games. Due to the game engine's popularity, most AR/VR headsets use Unity as a development platform. Similarly, HoloLens uses Unity to develop the intended AR/MxR experiences.

The first step to transferring 3D models to the HoloLens is configuring the Unity development environment. There are two ways to achieve this. The first option is to use the Unity standard configuration procedures. The second option is to use the Mixed Reality Toolkit, which is a Unity package consisting of a collection of custom tools developed by Microsoft HoloLens team to facilitate the development and deployment of AR/MxR experiences to the device (HoloLens). This article uses the Mixed Reality Toolkit (figure 9).

The Mixed Reality Toolkit was downloaded from a Microsoft HoloLens GitHub repository and imported into a Unity project as an asset package. After importing the Toolkit, configuring the project environment was performed at two levels. The first level of configuration involves applying changes to the "Project Settings" using the "Apply Mixed Reality Project Settings" option from the Mixed Reality Toolkit menu bar (figure 9, step 2). This setting configures Unity at a project level. It needs to make sure that, the 'Settings for Universal Windows Platform' is selected, and the 'Virtual Reality Supported' 
box from XR settings list is checked (figure 9, step $3 \& 4$ ). This configuration includes scripting backend, rendering quality, and player settings. All configurations have been applied to the present 'scene created' in this specific Unity project.

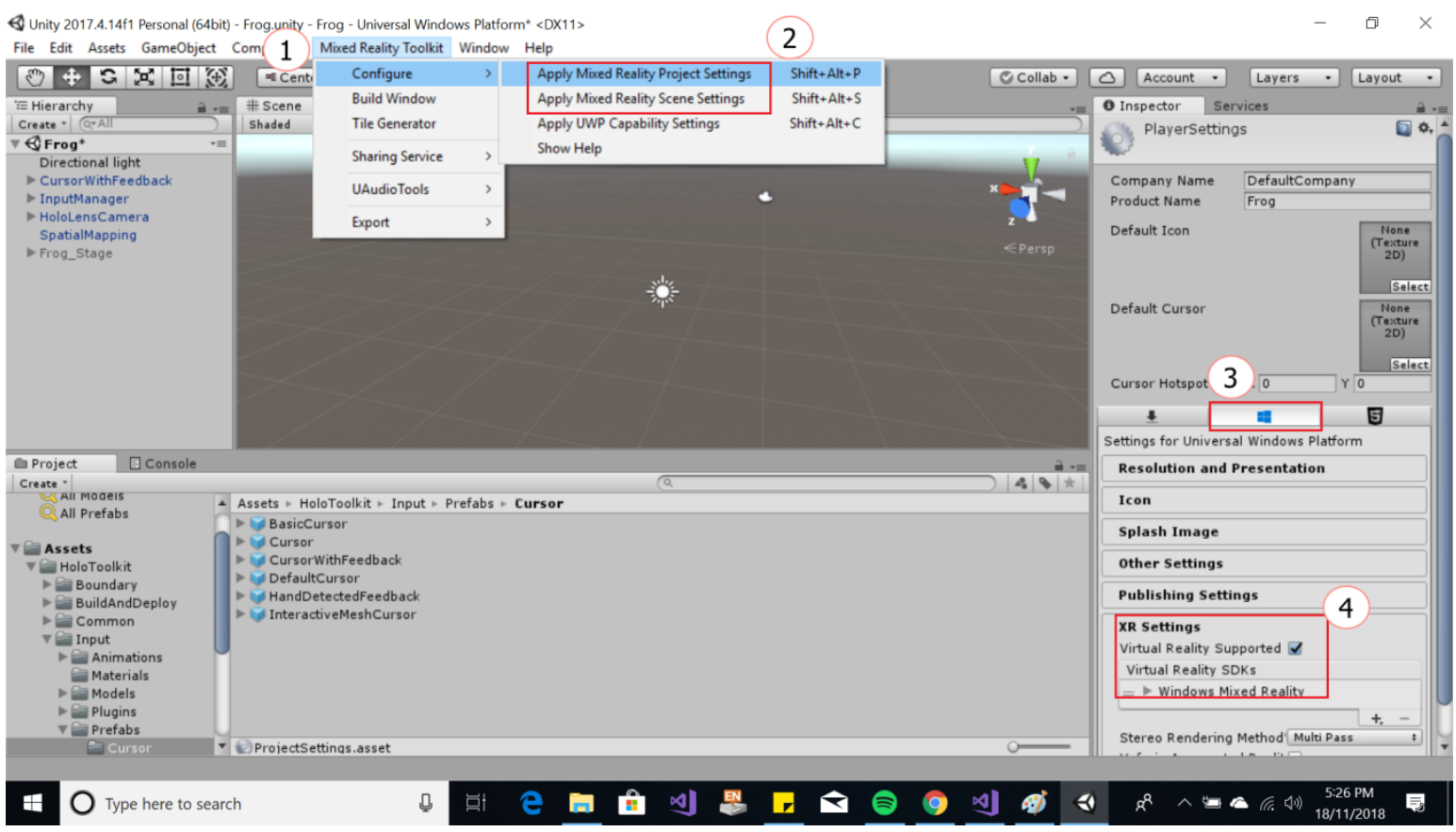

Figure 9. Configuring Unity project and scene settings to ensure compatibility with HoloLens.

The second level of configuration applies changes to a specific scene created 'under a project'. This has been achieved using the "Apply Mixed Reality Scene Settings" option from the Mixed Reality Toolkit menu bar (figure 9, step 2). For the scene level configuration, we used the toolkit to set the camera position, add the custom HoloLens camera, and configure background colour and rendering settings. After the proper configurations were applied to the "Project Settings" and "Scene Settings", the 3D model generated in section 4 was imported into the Unity project using the platform's asset importing option. Finally, gestural interactivity was implemented on the 3D model to allow users to interact with and manipulate the model via the default gestures recognised by the HoloLens. The Mixed Reality Toolkit has a number of scripts and tools for adding interaction mechanisms to the MxR experience. We have used the toolkit to add gestural and gaze-based interaction mechanisms.

\subsection{Building with Universal Windows Platform (UWP)}

Unity can build projects for a number of platforms. In this paper, however, the project was built for the Universal Windows Platform (UWP). UWP is an open source API developed by Microsoft and first introduced in Windows 10 (source: https://visualstudio.microsoft.com/vs/features/universal-windowsplatform, dated: $1^{\text {st }}$ March 2019). The purpose of this platform is to help develop universal apps that run on Windows 10, Windows 10 Mobile, Xbox One and HoloLens without the need to write codes for each target device. Hence, a single build can be deployed to multiple target devices. The steps followed before building the project for UWP were: adding a scene to the 'Built Settings', enabling C\# debugging; and specifying HoloLens as a target device.

Figure 10 shows how to configure the built environment and the steps of building the project for UW. First, it requires the user to select the 'Build Settings' from the File menu (figure 10, step $2 \& 3$ ) and click 'Add Open Scenes' and select the scenes opted for deployment (be sure that the scenes are listed in the 'Scenes In Build' box). A user needs to make sure the 'Universal Windows Platform' is selected as Platform and then select the HoloLens as 'Target Device' (step 4). Check the 'Unity C\# Projects' box to enable C\# debugging, and finally, click 'Build' (step $5 \& 6$ ). At this stage, all the files (including *.sin) required for project deployment to the HoloLens will be created and stored at a location specified by the user. 


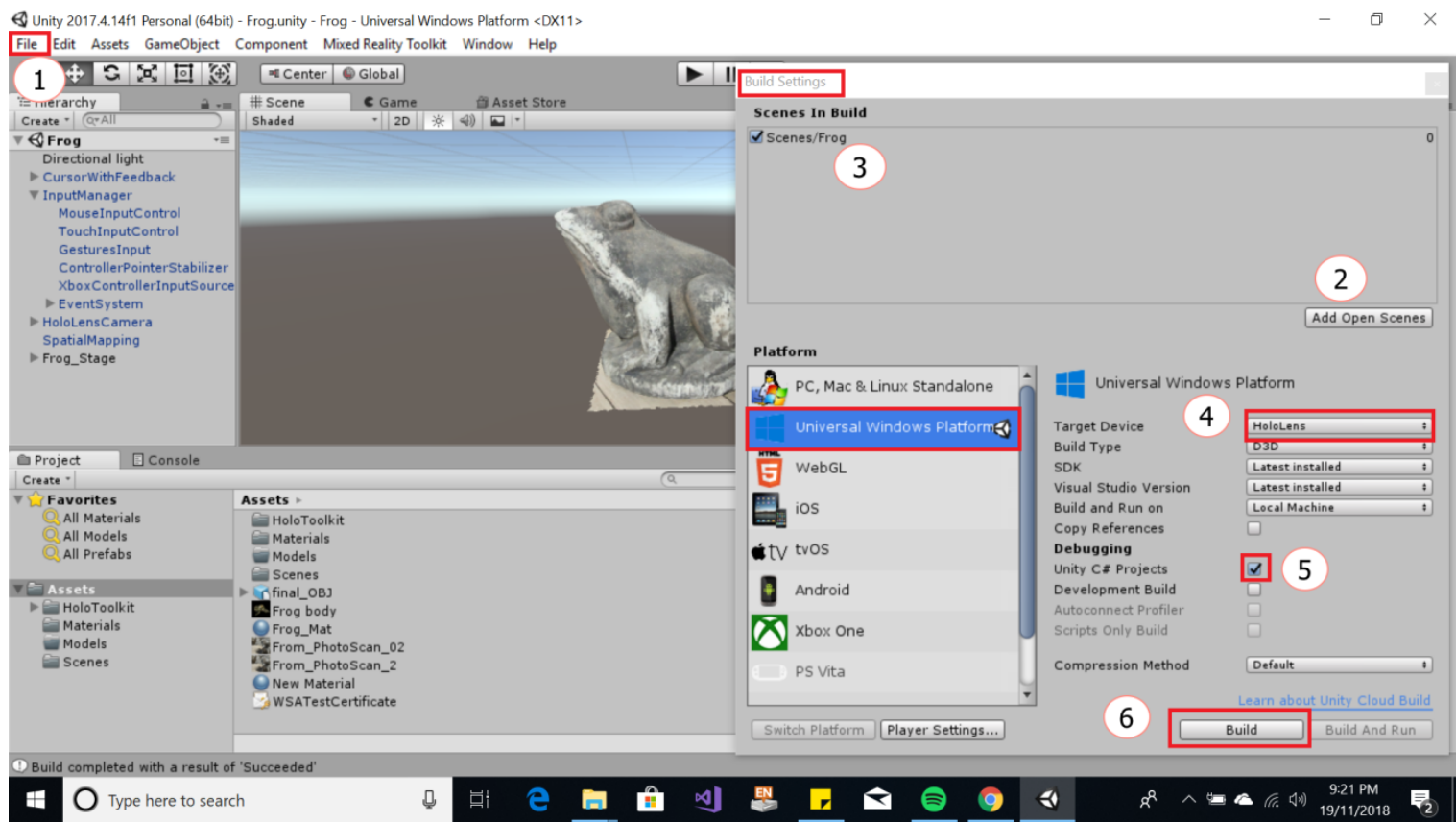

Figure 10. Building the project for Universal Windows Platform.

\subsection{Debugging with Microsoft Visual Studio and deploying to HoloLens}

At this stage, the *.sln file from the "Building with UWP" step discussed above is imported into Microsoft Visual Studio for debugging and deploying to HoloLens. Figure 11 shows the output of the deployment process. Deployment can commence by connecting the HoloLens via WiFi or using a USB cable and launching the deployment process from the Debug menu.

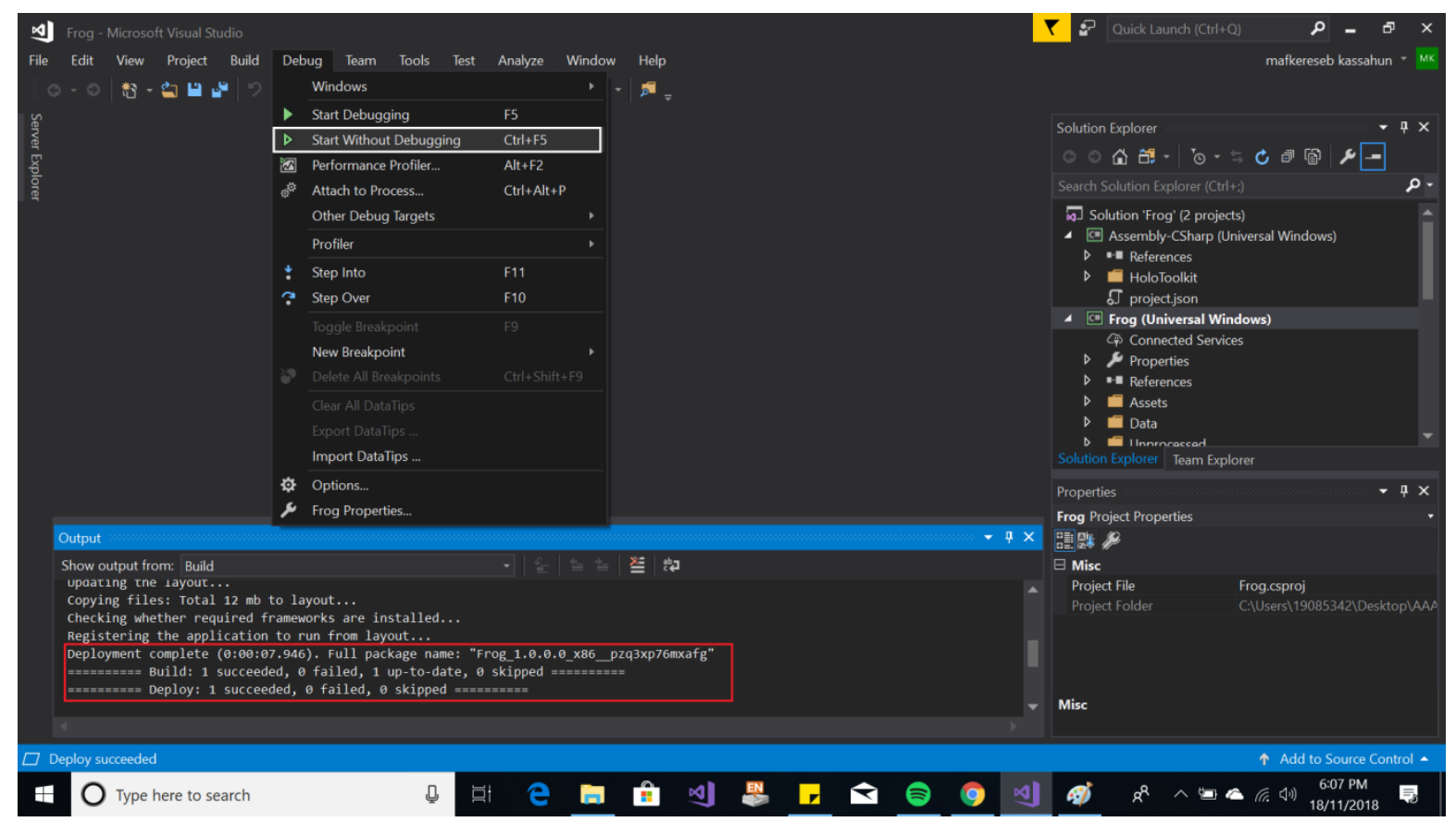

Figure 11. Debugging and deploying the solution to HoloLens using Visual Studio.

The HoloLens must be connected to the computer via USB and the *.sln file created during the build process is opened. To start the process, a user needs to select 'Start Without Debugging' from the 'Debug" pull-down menu (figure 11, step 1). The system will show the output details of the deployment process (figure 11, step 2). The user must make sure that the 'Deploy' count is 1 and 'failed' count is zero. If the deployment is successful, the HoloLens will launch the deployed application by itself. 


\subsection{Mixed reality experience in the HoloLens}

Usually, MxR experiences are developed to be used by a single user unless the experience is developed for collaborative use. After the application has been released into the HoloLens, a user can also connect the device to a bigger screen using WiFi for streaming the experience with others. It is difficult to imagine what the HoloLens user is experiencing unless the experience is shared. As a workaround to this issue, HoloLens allows the capturing and streaming of the users' view to another screen, as long as both devices are connected to the same WiFi network. In our case, we used this Mixed Reality Capture capability to stream the HoloLens user's experience (shown in Figure 12 below). There are a few seconds lag between the actual experience and the streaming of content to the other person's screen.

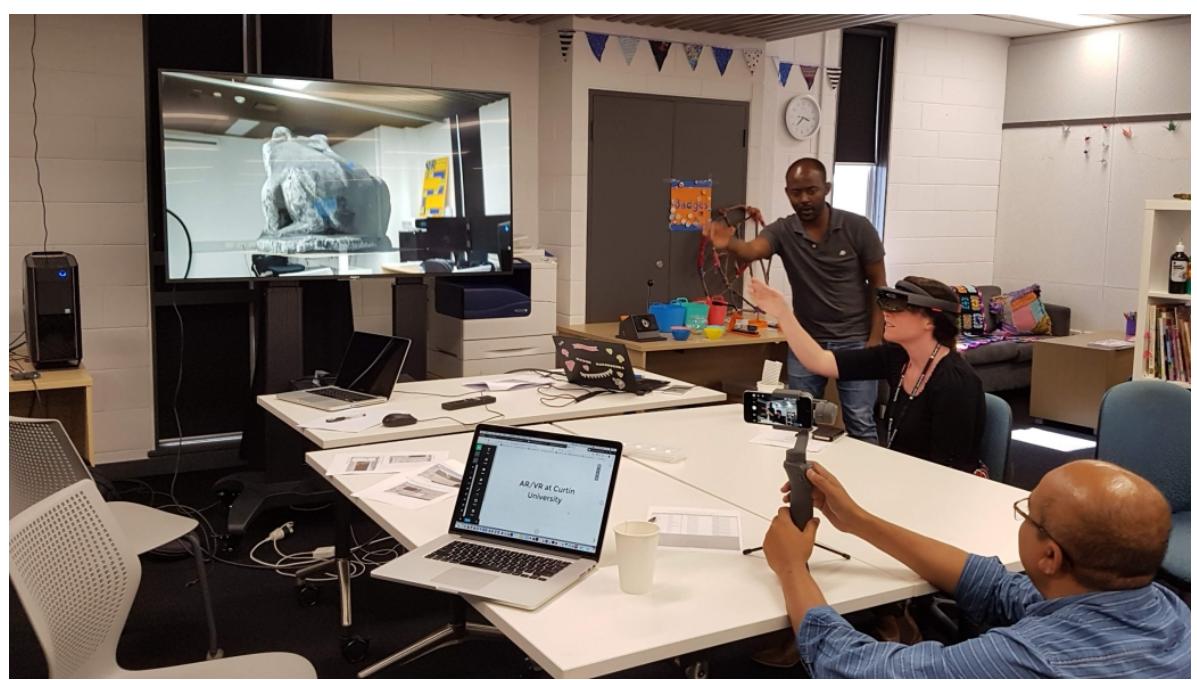

Figure 12. A user interacting with a 3D model via HoloLens.

\section{Demonstration and user feedback}

To validate the methodology a workshop was conducted at the Curtin library makerspace, Curtin University, Australia, on 23 November 2018. Fourteen participants attended the workshop, ranging from novice to expert computer users with an age range of 18 to 60 years. During the workshop, the data sets were supplied to the participants, and they were asked to follow the steps from the instructors. Most of the participants managed to produce the 3D model and reach the final level of deploying the content to the HoloLens. Due to the limited number of HoloLens (one set) and permitted time of the workshop (two hours), only one 3D asset was deployed and interactions were set with simple gestures. The environment with the embedded 3D assets was then shared with the participants to visualise and interact with them. The participants experienced the MxR environment and provided feedback in an informal post-experience discussion. This discussion, however, gives us some remarkable points to ponder for the future:

- Partial workflow (i.e. 3D modelling, editing and AR/VR visualisation with the FOSS) is supported by cross platforms. However, deployment of 3D assets to HoloLens (for MxR) requires Windows 10 operating systems, which prohibited the Mac operating system users from immediate participation or for following the workflow.

- The workflow was found to be workable and easy to follow. The learning of the gesture control to interact the 3D models in a MxR environment based on HoloLens requires time and practise for first-time users. However, they managed to learn the gestures within a short period.

- The workshop duration was limited to two hours, which evoked complaints from the participants, and we were advised to host an extended session.

\section{Conclusion}

In this paper, we present a complete workflow for experiencing a 3D model in a MxR environment captured from real-world objects by using proprietary and open access software and service. The workflow starts with digitising 3D artefacts based on image-based photo modelling (photogrammetry), 
converting a 3D point cloud to a $3 \mathrm{D}$ mesh, saving and sharing the $3 \mathrm{D}$ model to an online repository, viewing the $3 \mathrm{D}$ model in VR/AR, and finally deploying the 3D content to a MxR environment (MS HoloLens) and interacting with the virtual content.

The workflow was demonstrated to fourteen participants in a workshop session, and the users' feedback was collected. User feedback validates the workflow as easy to learn, workable and effective; with a few minor issues. We therefore believe this paper will help non-expert users, as well as small museums, heritage institutes, interested communities and local groups who are interested in digitising their 3D collections, sharing them online and visualising the 3D contents in an AR/VR/MxR environment; especially if their budget is limited and they do not have extensive experience in photogrammetry, modelling, or programming.

\section{References}

Amin, D., Govilkar, S., 2015. Comparative Study of Augmented Reality Sdks. International Journal on Computational Science \& Applications 5, 11-26.

Anderson, E.F., McLoughlin, L., Liarokapis, F., Peters, C., Petridis, P., De Freitas, S.J.V.r., 2010. Developing Serious Games for Cultural Heritage: A State-of-the-art Review. Virtual Reality 14, 255-275.

Barry, A., Thomas, G., Debenham, P., Trout, J., 2012. Augmented Reality in i Public Space: The Natural History Museum, London. Computer 45, 42-47.

Barsanti, S.G., Remondino, F., Fenández-Palacios, B.J., Visintini, D., 2014. Critical Factors and Guidelines for 3D Surveying and Modelling in Cultural Heritage. International Journal of Heritage in the Digital Era 3, 141-158.

Baskaran, A., 2018. Holograms and History, Inside the Collection. Museum of Applied Arts \& Sciences.

Bekele, M.K., Pierdicca, R., Frontoni, E., Malinverni, E.S., Gain, J., 2018. A Survey of Augmented, Virtual, and Mixed Reality for Cultural Heritage. Journal on Computing and Cultural Heritage 11, 1-36.

Bernardini, F., Mittleman, J., Rushmeier, H., Silva, C., Taubin, G., 1999. The Ball-Pivoting Algorithm for Surface Reconstruction. IEEE transactions on visualization and computer graphics 5, 349-359.

Bolognesi, M., Furini, A., Russo, V., Pellegrinelli, A., Russo, P., 2014. Accuracy of Cultural Heritage 3D Models by RPAS and Terrestrial Photogrammetry, pp. 113-119.

Bottino, A.G., García, A.M., Occhipinti, E., 2017. Holomuseum: A Prototype of Interactive Exhibition with Mixed Reality Glasses HoloLens.

Bruno, F., Bruno, S., De Sensi, G., Luchi, M.-L., Mancuso, S., Muzzupappa, M., 2010. From 3D Reconstruction to Virtual Reality: A Complete Methodology for Digital Archaeological Exhibition. Journal of Cultural Heritage 11, 42-49.

Carmigniani, J., Furht, B., Anisetti, M., Ceravolo, P., Damiani, E., Ivkovic, M., 2010. Augmented reality technologies, systems and applications. Multimedia Tools and Applications 51, 341-377.

Champion, E., 2018. The Role of 3D Models in Virtual Heritage Intrastructures, in: Benardou, A., Champion, E., Dallas, C., Hughes, L.M. (Eds.), Cultural Heritage Infrastructures in Digital Humanities. NY Routledge, Abingdon, Oxon New York, p. 172.

Comes, R., Neamțu, C., Buna, Z., Badiu, I., Pupeză, P., 2014. Methodology to Create 3D Models for Augmented Reality Applications Using Scanned Point Clouds. Mediterr Archaeol Ar 14, 35-44.

Curless, B., Levoy, M., 1996. A Volumetric Method for Building Complex Models From Range Images, Proceedings of the $23 \mathrm{rd}$ annual conference on Computer graphics and interactive techniques. ACM, pp. 303-312.

Deseilligny, M.P., Luca, L.D., Remondino, F., 2011. Automated Image-Based Procedures for Accurate Artifacts 3D Modeling And Orthoimage Generation, Proc. CIPA.

Durand, H., Engberg, A., Pope, S.T., 2011. A Comparison of 3d Modeling Programs. ATON Project/CREATE, Department of Music, University of California, Santa Barbara, USA, pp.1-9.

Gkion, M., Patoli, M., White, M., 2011. Museum Interactive Experiences Through a 3D Reconstruction of the Church of Santa Chiara, IASTED Computer Graphics and Virtual Reallity Conference, Cambridge, United Kingdom.

Grussenmeyer, P., Al Khalil, O., 2008. A Comparison of Photogrammetry Software Packages for the Documentation of Buildings.

Guidazzoli, A., Liguori, M.C., Chiavarini, B., Verri, L., Imboden, S., De Luca, D., Ponti, F.D., 2017. From 3D Web to VR historical scenarios: A Cross-media Digital Heritage Application for Audience Development, Virtual System \& Multimedia (VSMM), 2017 23rd International Conference on. IEEE, pp. 1-8. 
Haydar, M., Roussel, D., Maïdi, M., Otmane, S., Mallem, M.J.V.r., 2011. Virtual and Augmented Reality for Cultural Computing and Heritage: A Case Study of Virtual Exploration of Underwater Archaeological Sites (preprint). Virtual Reality 15, pp.311-327.

Kazhdan, M., Hoppe, H., 2013. Screened Poisson Surface Reconstruction. ACM Transactions on Graphics (ToG) 32, 29.

Knapitsch, A., Park, J., Zhou, Q.-Y., Koltun, V., 2017. Tanks and Temples: Benchmarking Large-scale Scene Reconstruction. ACM Transactions on Graphics (TOG) 36, 78.

Lab, D., 2018. Getting Started: A Guide to Photogrammetry, 3D Capturing Technology. University of Michigan 3D Lab, Michigan, USA, p. 16.

Mancera-Taboada, J., Rodríguez-Gonzálvez, P., González-Aguilera, D., Finat, J., San José, J., Fernández, J.J., Martínez, J., Martínez, R., 2011. From the Point Cloud to Virtual and Augmented Reality: Digital Accessibility for Disabled People in San Martin's Church (Segovia) and its Surroundings, International Conference on Computational Science and Its Applications. Springer, pp. 303-317.

Milgram, P., Kishino, F., 1994. A taxonomy of mixed reality visual displays. IEICE Transactions on Information and Systems 77, 1321-1329.

Monaghan, D., O'Sullivan, J., O'Connor, N.E., Kelly, B., Kazmierczak, O., Comer, L., 2011. Low-cost Creation of a 3D Interactive Museum Exhibition, Proceedings of the 19th ACM international conference on Multimedia. ACM, pp. 823-824.

Nguyen, M.H., Wünsche, B., Delmas, P., Lutteroth, C., 2012. 3D Models from the Black Box: Investigating the Current State of Image-Based Modeling, Proceedings of the 20th International Conference on Computer Graphics, Visualisation and Computer Vision (WSCG 2012), Pilsen, Czech Republic, June.

Nikolov, I., Madsen, C., 2016. Benchmarking Close-range Structure from Motion 3D Reconstruction Software Under Varying Capturing Conditions, Euro-Mediterranean Conference. Springer, pp. 15-26.

Oniga, E., Chirilă, C., Stătescu, F., 2017. Accuracy Assessment of a Complex Building 3d Model Reconstructed from Images Acquired with a Low-Cost Uas, ISPRS-International Archives of the Photogrammetry, Remote Sensing and Spatial Information Sciences, Nafplio, Greece, pp. 551-558.

Papagiannakis, G., Geronikolakis, E., Pateraki, M., López-Menchero, V.M., Tsioumas, M., Sylaiou, S., Liarokapis, F., Grammatikopoulou, A., Dimitropoulos, K., Grammalidis, N., 2018. Mixed Reality, Gamified Presence, and Storytelling for Virtual Museums. Encyclopedia of Computer Graphics Games, 1-13.

Pollalis, C., Fahnbulleh, W., Tynes, J., Shaer, O., 2017. HoloMuse: Enhancing Engagement With Archaeological Artifacts Through Gesture-based Interaction with Holograms, Proceedings of the Eleventh International Conference on Tangible, Embedded, and Embodied Interaction. ACM, pp. 565570.

Pollalis, C., Gilvin, A., Westendorf, L., Futami, L., Virgilio, B., Hsiao, D., Shaer, O., 2018. ARtLens: Enhancing Museum Visitors' Engagement with African Art, Proceedings of the 19th International ACM SIGACCESS Conference on Computers and Accessibility. ACM, pp. 195-200.

Pollalis, C., Minor, E., Westendorf, L., Fahnbulleh, W., Virgilio, I., Kun, A.L., Shaer, O., 2018. Evaluating Learning with Tangible and Virtual Representations of Archaeological Artifacts, Proceedings of the Twelfth International Conference on Tangible, Embedded, and Embodied Interaction. ACM, pp. 626637.

Portalés, C., Lerma, J.L., Pérez, C., 2009. Photogrammetry and Augmented Reality for Cultural Heritage Applications. The Photogrammetric Record 24, 316-331.

Potenziani, M., Callieri, M., Dellepiane, M., Corsini, M., Ponchio, F., Scopigno, R., 2015. 3DHOP: 3D Heritage Online Presenter. Comput Graph-Uk 52, pp.129-141.

Rahaman, H., Champion, E., 2019. From Images to 3D Reconstruction: A Feature Comparison on Proprietary and Open Access Photogrammetry Workflow for Cultural Heritage. Digital Humanities Quarterly, (manuscript submitted for publication).

Raptis, G.E., Fidas, C., Avouris, N., 2018. Effects of mixed-reality on players' behaviour and immersion in a cultural tourism game: A cognitive processing perspective. International Journal of HumanComputer Studies 114, 69-79.

Rua, H., Alvito, P., 2011. Living the Past: 3D models, Virtual Reality and Game Engines as Tools for Supporting Archaeology and the Reconstruction of Cultural Heritage - The Case-study of the Roman Villa of Casal de Freiria. Journal of Archaeological Science 38, 3296-3308.

Santagati, C., Inzerillo, L., Di Paola, F., 2013. Image Based Modeling Techniques for Architectural Heritage 3D Digitalization: Limits and Potentialities, International Archives of the Photogrammetry, Remote Sensing and Spatial Information Sciences, XXIV International CIPA Symposium, Strasbourg, France. 
Scott, M.J., Parker, A., Powley, E., Saunders, R., Lee, J., Herring, P., Brown, D., Krzywinska, T., 2018. Towards an Interaction Blueprint for Mixed Reality Experiences in GLAM Spaces: The Augmented Telegrapher at Porthcurno Museum.

Van Krevelen, D., Poelman, R., 2010. A survey of Augmented Reality Technologies, Applications and Limitations. International journal of virtual reality $9,1$.

Wang, F.-Y.J.I.I.S., 2009. Is culture computable?, pp. 2-3.

Wang, Y.-F., 2011. A Comparison Study of Five 3D Modeling Systems Based on the SfM Principles. Technical Report 2011-01. Visualize Inc., Goleta, USA, pp. 1-30.

Wu, H.-K., Lee, S.W.-Y., Chang, H.-Y., Liang, J.-C., 2013. Current Status, Opportunities and Challenges of Augmented Reality in Education. Computers \& education 62, pp. 41-49. 